\title{
Is Men's Heterosexuality Perceived as More Precarious than Women's? An Intersectional, Race-by-Gender Analysis
}

\author{
Christopher D. Petsko ${ }^{1}$, and Stefan Vogler ${ }^{3}$ \\ ${ }^{1}$ University of North Carolina at Chapel Hill \\ ${ }^{2} \mathrm{NORC}$ at the University of Chicago
}

\begin{abstract}
Author Note
Christopher D. Petsko (D) https://orcid.org/0000-0002-8795-0003

Stefan Vogler (D) https://orcid.org/0000-0001-7166-5999
\end{abstract}

This is a preprint of a paper that is in press at Personality and Social Psychology Bulletin. Please note that this version of the manuscript is not the version of record, as it has not yet been processed by the journal's editorial office. Data collection for this manuscript was possible because of an NSF-funded research award from the TESS program. All data, survey materials, supplemental analyses, and R scripts associated with this project are available on the Open Science Framework website: https://osf.io/bg9mj/. The authors are grateful to Tony Silva for his thoughtful comments on earlier iterations of this manuscript. Correspondence concerning this article should be directed to Christopher D. Petsko: christopher petsko@kenan-flagler.unc.edu 


\begin{abstract}
People perceive men's masculinity to be more precarious, or easier to lose, than women's femininity. In the present manuscript, we investigated (1) whether men's heterosexuality is likewise perceived to be more precarious than women's, and if so, (2) whether this effect is exaggerated when the targets in question are Black rather than White. To investigate these questions, we conducted three experiments (one of which was conducted on a probability-based sample of U.S. adults; total $N=3,811$ ) in which participants read about a target person who either did or did not engage in a single same-sex sexual behavior. Results revealed that participants questioned the heterosexuality of men more than the heterosexuality of women when they engaged (vs. did not engage) in same-sex sexual behavior. Surprisingly, these effects were not moderated by whether targets were Black vs. White. Results are interpreted in light of recent models of intersectional stereotyping.
\end{abstract}

Keywords: gender beliefs, stereotyping, intersectionality, person perception, precarious masculinity 


\section{Is Men's Heterosexuality Perceived as More Precarious than Women's? An Intersectional, Race-by-Gender Analysis}

In many cultures around the world, people perceive men's masculinity to be more precarious, or “easier to lose," than women’s femininity (e.g., Gilmore, 1990; Johnson \& LipsettRivera, 1998). One such society in which men's masculinity is regarded as more precarious than women's femininity is that of the United States (DiMuccio \& Knowles, 2021; Parent et al., 2018; Vandello \& Bosson, 2013). For example, in the U.S., people have an easier time making sense of the ambiguous statements "I used to be a man. Now I am no longer a man" than an otherwise identical set of statements that uses the word "woman" in place of the word "man" (Vandello et al., 2008). Moreover, when people read statements such as these, they often assume that lost masculinity is attributable to specific behaviors (e.g., failing to provide for one's family, or not being able to perform sexually), whereas they often assume that lost femininity is attributable to biological changes (e.g., losing one's vitality with age). Thus, in the U.S., men more than women have gender identities that can be lost in the eyes of perceivers when they engage in behaviors that seem incongruent with their prescribed gender roles.

The present manuscript examines whether a person's heterosexuality is likewise an identity that can be "lost" in the eyes of perceivers when that person engages in behaviors that seem incongruent with opposite-sex attraction. The hypothesis under scrutiny is that if heterosexuality is precarious (i.e., easily lost in the eyes of perceivers), it will be more precarious for men than for women. The basis for this hypothesis is that in the U.S., men and women are typically presumed to be heterosexual by default (Alt et al., 2020; Herek \& McLemore, 2013; Lick \& Johnson, 2016). Given that what it means to be a man in the eyes of perceivers is more precarious than what it means to be a woman, and given as well that what it means to be a man 
or woman presumes heterosexuality by default, we predict that one's sexual identity, much like one's gender identity, will be more precarious for men than for women.

Beyond examining this main hypothesis — which, to be sure, has already received some empirical support (Mize \& Manago, 2018; Tornello \& Matsik, 2020; West et al., 2021) — the present analysis sought to take an intersectional look at the research question under scrutiny. The term intersectionality was developed in Black feminist scholarship as a tool for thinking about the ways in which systems of oppression mutually reinforce one another (e.g., Crenshaw, 1991; King, 1988). In psychological science, intersectionality often refers more specifically to the epistemological stance that basic psychological phenomena, like how one is perceived, can depend on the multiple social groups to which one belongs (Cole, 2009). Relevant to the present manuscript, research on intersectional stereotyping (in the U.S.) reveals that perceptions of a person's gender can often be augmented or attenuated by whether that person is Black vs. White (Galinsky et al., 2013; Johnson et al., 2012). For example, there is evidence that Black men tend to be stereotyped as more masculine and more heterosexual than White men (Carnaghi et al., 2020; Hall et al., 2015; Johnson \& Ghavami, 2011). In addition, there is evidence that people think of White women as being more prototypically feminine than Black women (Goff et al., 2008; Hall et al., 2019), and that for this reason, people occasionally neglect to attend to what it is that Black women look like and say (Neel \& Lassetter, 2019; Sesko \& Biernat, 2010). In other words, there is evidence that Black women, relative to White women, can be rendered intersectionally invisible in the minds of perceivers (Ponce de Leon \& Rosette, 2022).

In light of these findings, we examined whether the precariousness of one's heterosexuality would depend on both the gender and the race of the person being perceived. In particular, we examined whether the tendency for men's heterosexuality to be regarded as more 
precarious than women's would be exaggerated when the men and women in question are Black rather than White. The basis for this prediction was that (a) if Black men (vs. White men) are stereotyped as especially heterosexual (Carnaghi et al., 2020), then Black men's same-sex sexual behavior may seem especially noticeable to perceivers. Likewise, (b) if Black women (vs. White women) are rendered intersectionally invisible in the minds of perceivers - so much so that that perceivers forget what Black women look like and say (Sesko \& Biernat, 2010) - then Black women's same-sex sexual behavior may seem less noticeable to perceivers. Thus, there is reason to believe that the tendency to perceive men's heterosexuality as more precarious than women's will be more pronounced when the men and women in question are Black rather than White.

Notably, the intersectional patterns described in the preceding paragraph are conceptually distinct from earlier theorizing on why some social groups have more precarious sexualities than others. According to earlier theorizing (Mize \& Manago, 2018), the factor that ought to govern how precarious one's heterosexuality is perceived to be is how large the gap in perceived social status is between heterosexual and non-heterosexual members of one's group. For example, the theoretical argument for why men's heterosexuality is more precarious than women's is that men have "more to lose" - in terms of their perceived social status - if they are presumed to be gay (vs. not). Given that Black individuals are stereotyped as lower-status than White individuals in the U.S. (e.g., Freeman et al., 2011; Petsko \& Bodenhausen, 2019b), it stands to reason that Black men, for example, may have "less to lose" — in terms of their perceived social status — than White men when they are presumed to be gay (vs. not). If this is indeed the case, then earlier theorizing might suggest that Black men's heterosexuality is less precarious than White men's. In contrast, if our line of reasoning is correct, then the opposite should be true; Black men ought to have heterosexualities that are perceived as more precarious than those of White men, not less. 


\section{Overview of Experiments}

The present manuscript begins with a description of two pilot experiments-Experiments 1a and $1 \mathrm{~b}$ - which afforded preliminary tests of whether gender (Experiment $1 \mathrm{a} ; N=400)$ and race (Experiment 1b; $N=401$ ), respectively, influence how precarious a person's heterosexuality is perceived to be. In the wake of these experiments, we conducted Experiment $2(N=3,010)$, which was a large-scale, nationally representative experiment that manipulated both target race (Black, White) and target gender (woman, man) simultaneously. The data for Experiments 1a and $1 \mathrm{~b}$ were collected via Amazon.com's MTurk. The data for Experiment 2 were collected via NORC's AmeriSpeak(C) Panel, which conducts probability-based random sampling from the U.S. adult population. ${ }^{1}$ Across experiments, our focal research questions were (1) whether men's heterosexuality would be perceived as more precarious than women's, and if so, (2) whether this effect would be exaggerated when the targets in question were Black rather than White. All experiments had institutional review board approval, and they report all manipulations and exclusions. Data files, survey materials, and R scripts associated with this project are available on the Open Science Framework (OSF) website: https://osf.io/bg9mj/. Throughout this manuscript, raw effect sizes will be reported as mean differences $\left(M_{\mathrm{diffs}}\right)$, and standardized effect sizes, which will be encompassed by $95 \%$ confidence intervals (95\% CIs), will be reported as standard betas $(\beta \mathrm{s})$. Statistical power for detecting main effects and interactions will be described in the results section of each experiment. ${ }^{2}$

\footnotetext{
${ }^{1}$ Data collection for Experiment 2 was made possible because of an NSF-funded research award from TESS (TimeSharing Experiments for the Social Sciences; Craig et al., 2022).

${ }^{2}$ In the service of brevity, we will not discuss every effect from every model that we ran. However, complete reporting of all model effects - with 95\% confidence intervals around unstandardized and standardized estimates those effects - can be found in Tables S1 through S9 of the online supplement.
} 


\section{Experiments 1a and 1b}

Experiments $1 \mathrm{a}$ and $1 \mathrm{~b}$ were meant to provide preliminary tests of whether gender (Experiment 1a; $N=400$ ) and race (Experiment $1 \mathrm{~b} ; N=401$ ), respectively, influence how precarious a person's heterosexuality is perceived to be. In both experiments, participants read a vignette about a target person who either did or did not engage in a single same-sex sexual behavior. In Experiment 1a, target race was held constant — all targets were White — but targets' gender was manipulated (man, woman). In Experiment 1b, target gender was held constant—all targets were men — but targets' race was manipulated (Black, White). The hypotheses under scrutiny were (1) that heterosexuality would be perceived as more precarious for White men than for White women (Experiment 1a), and (2) that heterosexuality would be perceived as more precarious for Black men than for White men (Experiment 1b). In addition to measuring participants' perceptions of targets' heterosexuality, these experiments also measured participants' perceptions of targets' bisexuality and homosexuality. Thus, these experiments were able to measure the precariousness of a target person's heterosexuality not just by the magnitude by which engaging in same- (vs. opposite-) sex sexual behavior causes them to seem "less heterosexual" to perceivers, but likewise by the magnitude by which it causes them to seem "more gay" and "more bisexual" to perceivers.

\section{Method}

Participants made judgements about the sexual orientations of targets whose demographic features and behaviors we manipulated in vignette studies. Experiment 1a had a 2 (target gender: man, woman) $\times 2$ (target behavior: opposite-sex behavior, same-sex behavior) between-person experimental design. Experiment $1 \mathrm{~b}$ had a 2 (target race: Black, White) $\times 2$ (target behavior: opposite-sex behavior, same-sex behavior) between-person experimental design. 


\section{Participants}

Our a priori goal was to have $n=100$ people per condition in Experiments 1a and 1b. In total, $N=801$ people were recruited from Amazon.com's MTurk platform to complete these experiments in exchange for $\$ 0.25$. Of these participants, we excluded $n=7(0.87 \%)$ for not responding "yes" to the question, "Did you take this survey seriously?" The remaining participants were mostly male (427 male, 360 female, 3 other, and 4 non-specified), mostly White (566 White, 68 Asian, 65 Black, 43 multiracial, 39 Latinx, 8 Native American, 2 Pacific Islander, 1 other, 2 non-specified), and mostly heterosexual ( 707 heterosexual, 44 bisexual, 25 gay or lesbian, 4 other, and 14 non-specified). In addition, participants were diverse in terms of their political leanings $(M=4.38, S D=2.89$, on a scale from $0=$ extremely liberal to $10=$ extremely conservative), diverse in terms of age (ranging from 19 to $81 ; M=35.59, S D=10.67$ ), and generally well-educated (56.9\% held a bachelor's degree or higher).

\section{Procedure}

Participants were told that we were interested in understanding how they perceived people based on people's life histories and behaviors. Regardless of the experiment or condition, participants were then shown a vignette with the following structure:

Consider Hunter, a man who has only had romantic and sexual relationships with women and who has found those relationships to be satisfying. One night, Hunter meets another man in a bar and finds him attractive. At the end of the night, they go home together and have a casual sexual encounter.

The protagonist of the vignette was always described as having an opposite-sex dating history. The behavior of the protagonist was manipulated such that they either had a sexual encounter with someone of the same sex (depicted in the example above) or with someone of the opposite 
sex. This modification was made by changing the words "man" to "woman" (or vice versa) where appropriate, and by changing corresponding gender pronouns to match these modifications. In Experiment 1a, all the targets were White, but varied in their gender. In Experiment 1b, all the targets were men, but varied in their race. To manipulate targets' racial groups and gender groups, we used names that have been normed (on an internet sample of more than $N=8,000$ participants; Gaddis, 2017) as implying that a target person is White or Black at least $80 \%$ of the time. In Experiment 1a, participants either saw one of 15 names that were normed to be stereotypic of White men (e.g., Hunter, Jake, Seth) or they saw one of 15 names that were normed to be stereotypic of White women (e.g., Katelyn, Claire, Megan). In Experiment $1 \mathrm{~b}$, participants either saw one of 15 names that were normed to be stereotypic of Black men (e.g., DaShawn, Tremayne, Jamal) or they saw one of 15 names that were normed to be stereotypic of White men (e.g., Hunter, Jake, Seth). For the full list of stimulus names used in the present experiments, see Table $1 .^{3}$

After reading the passage, participants then rated their certainty in targets' heterosexuality, bisexuality, and homosexuality, respectively. The order in which participants made each of these ratings was randomized, and ratings were provided on sliding scales from 0 to 100 . On these scales, 0 indicated total certainty that the focal person was not an orientation, 100 indicated total certainty that the focal person was an orientation, and 50 indicated uncertainty about whether the focal person was or was not of a particular orientation (for a similar approach, see Mize \& Manago, 2018). Finally, participants answered an open-ended question about why they thought the protagonist behaved the way that they did, as well as a

\footnotetext{
${ }^{3}$ The decision to use a wide range of stimulus names was meant to serve as a methodological improvement over earlier work that has examined perceptions of sexual precarity (e.g., Mize \& Manago, 2018). In general, stimulus variety of this kind reduces the risk of making a type I error and increases the generality of one's statistical conclusions (e.g., Judd et al., 2012).
} 
checklist measure of the traits they associated with the protagonist (Katz \& Braly, 1933). These latter two measures were included for exploratory purposes and were not analyzed in detail. As such, they are not discussed further.

\section{Table 1}

Stimulus Names Implicating Each of Four Race-by-Gender Intersections

Name Type

\begin{tabular}{|c|c|c|c|}
\hline White Man & White Woman & Black Man & Black Woman \\
\hline Hunter & Katelyn & DaShawn & Tanisha \\
\hline Jake & Claire & Tremayne & Lakisha \\
\hline Seth & Laurie & Jamal & Tamika \\
\hline Zachary & Megan & DaQuan & Latoya \\
\hline Todd & Kristen & DeAndre & Keyana \\
\hline Matthew & Emily & Tyrone & Latonya \\
\hline Ryan & Sarah & Keyshawn & Shanice \\
\hline Scott & Molly & Latrell & Tyra \\
\hline Dustin & Jill & Jayvon & Ebony \\
\hline Brett & Hilary & Darnell & Denisha \\
\hline Ethan & Meredith & Lamar & Keisha \\
\hline Connor & Amy & Terell & Aisha \\
\hline Steven & Susan & Darius & Ashanti \\
\hline Luke & Allison & Kareem & Precious \\
\hline Graham & Anne & Jermaine & Kenya \\
\hline
\end{tabular}

Note. Each of these men's and women's names have been normed as implying their designated racial categories at least $80 \%$ of the time in previous large-scale studies (see Gaddis, 2017). Experiment 1a used White men's names and White women's names only. Experiment $1 \mathrm{~b}$ used White men's and Black men's names only. Experiment 2 used all 60 names.

\section{Results}

The data in Experiments $1 \mathrm{a}$ and $1 \mathrm{~b}$ were analyzed by regressing each dependent variable, in a multilevel model, onto contrast codes that represented the $2 \times 2$ factorial design of each experiment. These models always included just one random effect: a random effect of stimulus intercept, which adjusted for any variation in participant responding that was attributable to which specific stimulus name they had been assigned (e.g., Seth vs. Todd). Models of this sort 
are functionally equivalent to standard $2 \times 2$ ANOVAs, but they have the added benefit of reducing the likelihood of making a Type I error (Judd et al., 2012). According to Monte Carlo simulations, Experiments $1 \mathrm{a}$ and $1 \mathrm{~b}$ had at least $80 \%$ power to detect main effects as small as $\beta=$ 0.23, and to detect two-way interactions as small as $\beta=0.46$ (for more on this technique for simulating statistical power, see Bolger et al., 2012). ${ }^{4}$

\section{Experiment 1a: Precariousness as a Function of Targets' Gender Groups}

Because Experiment 1a had a 2 (target gender: man, woman) $\times 2$ (target behavior: opposite-sex behavior, same-sex behavior) between-person experimental design, this experiment afforded an examination of whether targets' gender groups moderate the extent to which their sexualities are regarded as precarious.

Perceived heterosexuality. Our first research question concerned whether men's heterosexuality would be perceived as more precarious than women's heterosexuality. To test whether this was the case, we subjected perceived heterosexuality scores in Experiment 1a to the 2 (target gender) $\times 2$ (target behavior) analysis described above. This analysis revealed evidence of a two-way interaction between target behavior and target gender: $\beta=-0.49,95 \% \mathrm{CI}[-0.81,-$ 0.18], $F(1,392)=9.55, p=.002$. Decomposing this interaction revealed that although targets in general tended to seem "less heterosexual" to participants when they engaged (vs. did not engage $)$ in a same-sex sexual behavior $\left[M_{\text {diff }}=-37.42, \beta=-1.17,95 \% \mathrm{CI}[-1.33,-1.02], F(1\right.$, $392)=214.56, p<.001]^{5}$, the magnitude of this effect was significantly larger when the targets were men $\left[M_{\text {diff }}=-45.31, \beta=-1.42,95 \% \mathrm{CI}[-1.64,-1.20], F(1,392)=158.96, p<.001\right]$ than when they were women $\left[M_{\text {diff }}=-29.53, \beta=-0.92,95 \% \mathrm{CI}[-1.15,-0.70] F(1,392)=66.10, p<\right.$

\footnotetext{
${ }^{4}$ All simulations were conducted using the "simr" package in R (Green \& MacLeod, 2015).

${ }^{5}$ Standard betas $(\beta s)$ were always computed by regressing z-standardized outcomes onto orthogonal condition contrasts that were centered around zero and that had a range of one. Under this analytic strategy, $\beta$ s for main effects can be interpreted similarly to Cohen's $d$ s.
} 
.001]. In other words, there was indeed evidence that men's heterosexuality was perceived as more precarious than women's (see Table 2, for condition means).

Table 2

Experiment 1a Condition Means: Does Target Gender Influence Sexual Precarity?

\begin{tabular}{|c|c|c|c|c|c|}
\hline \multicolumn{3}{|c|}{$\begin{array}{l}\text { Pilot Experiment 1a } \\
\qquad(N=396)\end{array}$} & \multicolumn{3}{|c|}{$\begin{array}{c}\text { Perceptions that Targets Were Each of Three } \\
\text { Specified Sexual Orientations }\end{array}$} \\
\hline $\begin{array}{c}\text { Target } \\
\text { Race }\end{array}$ & $\begin{array}{l}\text { Target } \\
\text { Gender }\end{array}$ & $\begin{array}{c}\text { Target } \\
\text { Behavior }\end{array}$ & Heterosexual & Bisexual & Homosexual \\
\hline White & Man & Control & $87.21(2.54)$ & $25.82(2.62)$ & $15.93(2.74)$ \\
\hline White & Man & Same-sex & $41.90(2.54)$ & $77.50(2.54)$ & $50.81(2.69)$ \\
\hline White & Woman & Control & $85.49(2.54)$ & $31.23(2.59)$ & $18.84(2.73)$ \\
\hline White & Woman & Same-sex & $55.96(2.59)$ & $63.99(2.58)$ & $33.22(2.74)$ \\
\hline
\end{tabular}

Note. Means are outside of parentheses; standard errors around those means are within. Scores of 0 indicate certainty that targets are not a given sexual orientation; scores of 50 indicate uncertainty about whether targets are a given sexual orientation; and scores of 100 indicate certainty that targets are a given sexual orientation.

Perceived bisexuality. What about perceived bisexuality? Was it the case that engaging in a single same-sex sexual behavior caused men, more than women, to seem bisexual to perceivers? To examine this possibility, bisexuality ratings in Experiment 1a were subjected to the same 2 (target gender) $\times 2$ (target behavior) analysis as above. This model revealed evidence of a two-way interaction between target behavior and target gender: $\beta=0.56,95 \% \mathrm{CI}[0.26$, $0.87], F(1,387)=13.40, p<.001$. The nature of this interaction was that although targets in general tended to seem "more bisexual" when they engaged (vs. did not engage) in a same-sex sexual behavior $\left[M_{\text {diff }}=42.22, \beta=1.26,95 \% \mathrm{CI}[1.11,1.41], F(1,387)=266.86, p<.001\right]$, the magnitude of this effect was significantly larger when the targets were men $\left[M_{\text {diff }}=51.68, \beta=\right.$ $1.54,95 \% \mathrm{CI}[1.33,1.76], F(1,387)=200.36, p<.001]$ than when the targets were women $\left[M_{\text {diff }}\right.$ $=32.76, \beta=0.98,95 \% \mathrm{CI}[0.76,1.19], F(1,387)=80.17, p<.001]$. Thus, as was the case previously, men's sexuality was more pliable in the eyes of perceivers than women's. Engaging 
in a single same-sex sexual behavior (vs. not) not only caused men, more than women, to seem "less heterosexual," but it likewise caused them to seem "more bisexual" (see Table 2, for condition means).

Perceived homosexuality. Finally, the design of Experiment la allowed us to test whether perceptions of homosexuality, like judgments of heterosexuality and bisexuality, were more pliable when the targets were men (vs. women). To test whether this was the case, ratings of how homosexual target individuals seemed were subjected to the same 2 (target gender) $\times 2$ (target behavior) analysis as above. This model revealed evidence of a two-way interaction between target behavior and target gender that corroborated what we found on the other two dependent variables: $\beta=0.68,95 \% \mathrm{CI}[0.32,1.03], F(1,389)=14.22, p<.001$. Although all targets seemed "more homosexual" when they engaged (vs. did not engage) in a same-sex sexual behavior $\left[M_{\text {diff }}=24.64, \beta=0.81,95 \% \mathrm{CI}[0.64,0.99], F(1,389)=82.05, p<.001\right]$, the magnitude of this effect was significantly bigger when the targets were men $\left[M_{\text {diff }}=34.89, \beta=\right.$ $1.15,95 \% \mathrm{CI}[0.90,1.40], F(1,391)=82.68, p<.001]$ than when they were women $\left[M_{\text {diff }}=\right.$ $14.39, \beta=0.47,95 \% \mathrm{CI}[0.23,0.72], F(1,385)=13.92, p<.001]$. Thus, men who engaged in a single same-sex sexual behavior (vs. not) seemed "gayer" to participants than women who did the same (see Table 2, for condition means).

\section{Experiment 1b: Precariousness as a Function of Targets' Racial Groups}

Because Experiment 1b had a 2 (target race: Black, White) $\times 2$ (target behavior: oppositesex behavior, same-sex behavior) between-person experimental design, this experiment afforded an examination of whether targets' racial groups moderate the extent to which their sexualities are regarded as precarious. 
Perceived heterosexuality. At the outset of this manuscript, we suggested that there is good reason to believe that Black men's heterosexuality may be perceived as more precarious than that of White men. Was there any evidence that this was the case? Subjecting judgments of targets' heterosexuality in Experiment $1 \mathrm{~b}$ to the 2 (target race) $\times 2$ (target behavior) analysis described above revealed evidence that all target men were judged as "less heterosexual" when they engaged in a same-sex hookup (vs. when they did not) $-M_{\text {diff }}=-49.49, \beta=-1.42,95 \%$ $\mathrm{CI}[-1.55,-1.28], F(1,387)=407.64, p<.001$ - but there was no evidence that this effect was moderated by whether the target men were Black vs. White [two-way interaction: $\beta=-0.16$, $95 \% \mathrm{CI}[-0.43,0.12], F(1,387)=1.27, p=.26]$. In short, then, we did not find evidence that a person's racial group moderated the extent to which their heterosexuality was perceived as precarious (see Table 3 , for condition means). ${ }^{6}$

Table 3

Experiment $1 \mathrm{~b}$ Condition Means: Does Target Race Influence Sexual Precarity?

\begin{tabular}{|c|c|c|c|c|c|}
\hline \multicolumn{3}{|c|}{$\begin{array}{l}\text { Pilot Experiment } 1 \mathrm{~b} \\
\qquad(N=398)\end{array}$} & \multicolumn{3}{|c|}{$\begin{array}{c}\text { Perceptions that Targets Were Each of Three } \\
\text { Specified Sexual Orientations }\end{array}$} \\
\hline $\begin{array}{l}\text { Target } \\
\text { Race }\end{array}$ & $\begin{array}{l}\text { Target } \\
\text { Gender }\end{array}$ & $\begin{array}{l}\text { Target } \\
\text { Behavior }\end{array}$ & Heterosexual & Bisexual & Homosexual \\
\hline Black & Man & Control & $87.41(2.45)$ & $21.55(2.46)$ & $14.44(2.65)$ \\
\hline Black & Man & Same-sex & $35.16(2.51)$ & $74.84(2.43)$ & $40.54(2.69)$ \\
\hline White & Man & Control & $91.59(2.47)$ & $19.95(2.46)$ & $9.43(2.67)$ \\
\hline White & Man & Same-sex & $44.85(2.51)$ & $72.64(2.41)$ & $42.12(2.66)$ \\
\hline
\end{tabular}

Note. Means are outside of parentheses; standard errors around those means are within. Scores of 0 indicate certainty that targets are not a given sexual orientation; scores of 50 indicate uncertainty about whether targets are a given sexual orientation; and scores of 100 indicate certainty that targets are a given sexual orientation.

\footnotetext{
${ }^{6}$ Unfortunately, a limitation of the present experiments is that we did not include manipulation checks related to targets' race or gender. Nevertheless, we wish to note that the use of these names to manipulate race has been extensively validated (see Gaddis, 2017), and that it is likely that a vast majority of participants made racial inferences about targets as intended.
} 
Perceived bisexuality. Was there any evidence that Black vs. White men seemed differentially "bisexual" as a result of engaging (vs. not engaging) in same-sex sexual behavior? As in the previous analysis, the 2 (target race) $\times 2$ (target behavior) model described above yielded a main effect of target behavior such that all targets were rated as "more bisexual" when they engaged (vs. did not engage) in a same-sex sexual behavior: $M_{\text {diff }}=52.99, \beta=1.49,95 \%$ $\mathrm{CI}[1.36,1.63], F(1,372)=479.13, p<.001$. However, the magnitude by which this occurred was not dependent on whether target men were Black vs. White [two-way interaction: $\beta=0.02$, $95 \% \mathrm{CI}[-0.25,0.28], F(1,372)=0.02, p=.90]$. Thus, although our theorizing would have predicted that engaging (vs. not engaging) in same-sex behavior would have been differentially consequential for White vs. Black men, we found no evidence to support this prediction (see Table 3, for condition means).

Perceived homosexuality. Finally, our experimental design allowed us to examine whether perceptions of "how homosexual" target men seemed would depend not just on their behavior (i.e., whether they did or did not engage in a same-sex sexual behavior), but on their racial groups as well. To examine this possibility, judgments of homosexuality were subjected to the same 2 (target race) $\times 2$ (target behavior) model described above. Again, we found evidence of a main effect of target behavior, suggesting that all of the target men seemed "more homosexual" to participants when they engaged (vs. did not engage) in a same-sex sexual behavior: $M_{\text {diff }}=29.39, \beta=0.97,95 \%$ CI $[0.80,1.14], F(1,394)=121.64, p<.001$. However, we again found no evidence that this bias was moderated by whether the target individuals were Black vs. White [two-way interaction: $\beta=-0.22,95 \% \mathrm{CI}[-0.56,0.13], F(1,394)=1.53, p=$ .22]. Thus, across the board, there was no evidence in Experiment $1 \mathrm{~b}$ that targets' race-like 
targets' gender - influenced the amount by which their sexual orientations were regarded as pliable in the minds of perceivers (see Table 3, for condition means).

\section{Discussion}

Experiments $1 \mathrm{a}$ and $1 \mathrm{~b}$ were meant to provide preliminary tests of whether targets' gender groups and racial groups, respectively, influence the extent to which perceivers regard their sexualities to be precarious. Experiment 1a revealed consistent evidence that targets' gender groups influence how precarious their sexualities are regarded to be. Although it is true that engaging in a same-sex sexual behavior causes everyone to seem "less heterosexual," "more bisexual," and "more gay" than they would seem otherwise, these effects are significantly stronger when the individuals exhibiting the behavior are men rather than women. These findings are sensible from the perspective that in the U.S., men's gender identities are regarded as more precarious than women's (Vandello \& Bosson, 2013), and that one's gender identity presumes heterosexuality by default (Alt et al., 2020). In addition, these findings lend credence to earlier research on this topic, which has suggested that men's heterosexuality might indeed be more precarious than women's (Mize \& Manago, 2018).

Surprisingly, the effects described above did not appear to be any stronger when the individuals exhibiting same- (vs. opposite-) sex sexual behavior were Black rather than White. That is, engaging in same-sex sexual behavior had no more pronounced an effect on how Black men's sexualities were perceived than it did on how White men's sexualities were perceived. Notably, this observation contradicts not only our theorizing, but likewise the theorizing of others who have written about this topic. For example, Mize and Manago's (2018) writing on this topic suggests that Black men's heterosexuality might be perceived as less precarious than White men's - at least insofar as the gap in perceived social status between heterosexual and gay 
Black men is smaller than that between heterosexual and gay White men. Our own writing on this topic, rooted in gendered-race findings (e.g., Hall et al., 2015), suggests that Black men's heterosexuality might be perceived as more precarious than White men's — at least insofar as Black men are stereotyped as hyper-heterosexual (Carnaghi et al., 2020). Yet neither of these possibilities was supported. Instead, it was as if perceivers barely considered targets' racial groups when making judgments about targets' sexual behaviors.

\section{Experiment 2: A Nationally Representative, Large-Scale Experiment}

Experiment $1 \mathrm{a}$ and $1 \mathrm{~b}$ have some limitations that preclude us from making strong conclusions about their findings. First, while Experiment 1a was able to examine how gender (controlling for race) influences judgments of sexual precarity, and while Experiment $1 \mathrm{~b}$ was able to examine how race (controlling for gender) influences sexual precarity, our research questions were meant to be about the joint impact of race and gender in shaping judgments of sexual precarity. A better experimental design for our purposes, therefore, would be one that includes Black women in addition to White women, Black men, and White men. Second, Experiments $1 \mathrm{a}$ and $1 \mathrm{~b}$ included only $n=100$ people per condition. While it could be the case that targets' racial groups truly do not influence how precarious their sexualities are perceived to be - at least in the context of the present vignette studies - it may as well be the case that the targets' racial groups do influence these judgments, but that they do so to a smaller degree than we had sufficient power to detect. A higher-powered test of our research questions, therefore, would enable us to speak more definitively to the question of whether targets' racial groups might, in tandem with their gender groups, influence the extent to which their sexualities are perceived to be precarious. Finally, these experiments were conducted on convenience samples and may therefore lack generalizability to the broader U.S. public. 
Experiment 2 was designed to be an improvement over Experiments $1 \mathrm{a}$ and $1 \mathrm{~b}$ in each of these regards. First, in Experiment 2, participants read about targets who were either Black men, Black women, White men, or White women. Second, whereas Experiments 1a and 1b had approximately $n=100$ people per condition, Experiment 2 had approximately $n=375$ per condition. And finally, the data for Experiment 2 were collected via NORC's AmeriSpeak ( Panel, which conducts probability-based random sampling from the U.S. adult population (data collection was made possible by a research award from TESS: Craig et al, 2022).

\section{Method}

In Experiment 2, participants made judgements about the sexual orientations of targets whose demographic features and behaviors we manipulated in a vignette study. The full design of Experiment 2 was a 2 (target race: Black, White) $\times 2$ (target gender: man, woman) $\times 2$ (target behavior: opposite-sex behavior, same-sex behavior) between-person experiment.

\section{Participants}

A total of $N=3,010$ participants completed this experiment. As noted, a unique feature of Experiment 2 is that its participants were representative of adults living in the United States. The sample itself was balanced in terms of gender identity (1525 women, 1485 men), approximated racial/ethnic demographics of the U.S. (1927 White, 488 Latinx, 361 Black, 91 multiracial, 89 Asian), and was mostly heterosexual (2634 heterosexual, 91 bisexual, 87 gay or lesbian, 26 other, 14 uncertain, and 158 non-responses). The sample was also diverse in terms of political leanings $(M=3.59, S D=1.67$, on a scale from $1=$ extremely liberal to $7=$ extremely conservative), age (ranging from 18 to $93 ; M=47.88, S D=16.70$ ), household income (ranging from under $\$ 5,000$ per year to over $\$ 200,000$ per year; median: $\$ 50,000$ to $\$ 59,999$ per year), and education level (33.8\% held a bachelor's degree or higher). 


\section{Procedure}

Participants completed an online survey that was conducted via NORC's AmeriSpeak C Panel, which conducts probability-based sampling from the U.S. adult population. Similar to Experiments $1 \mathrm{a}$ and $1 \mathrm{~b}$, all participants in Experiment 2 were shown a vignette. Note that to more closely align our vignette with that used in prior research on this topic (Mize \& Manago, 2018), the wording of our vignette was updated slightly:

DaShawn is currently single but has had multiple happy relationships with women in the past. DaShawn has only dated women and one of his relationships with a woman lasted for over two years. The other night, DaShawn met another man and felt attracted to him. At the end of the night, they went home together and had a casual sexual encounter. As before, the protagonist of the vignette was always described as having an opposite-sex dating history. The behavior of the protagonist was manipulated such that they either had a sexual encounter with someone of the same sex (depicted in the example above) or with someone of the opposite sex. To manipulate the race and gender of the protagonist, one name was drawn randomly from a list of 60 names. Of the 60 names, 15 were ostensible White men's names, 15 were ostensible White women's names, 15 were ostensible Black men's names, and 15 were ostensible Black women's names (see Table 1 for the complete list of names). ${ }^{7}$ After reading the passage, participants completed the same three dependent variables as in Experiments 1a and 1b. That is, participants rated their certainty that the focal person was heterosexual, bisexual, and homosexual. Finally, for exploratory purposes, participants answered an open-ended question

\footnotetext{
${ }^{7}$ Due to a programming error, the name "Jermaine" was accidentally used in place of the name "Aisha" in Experiment 2. All statistical conclusions hold whether we do or do not eliminate participants who were impacted by this error, and we therefore continue to report results across the entire sample.
} 
about why they thought the protagonist behaved the way that they did. Responses to this final question were not analyzed and are not discussed further.

\section{Results}

Data from Experiment 2 were analyzed by regressing each dependent variable, in a multilevel model, onto contrast codes representing the full $2 \times 2 \times 2$ factorial design of this experiment. These models included just one random effect: a random effect of stimulus intercept, which adjusted for any variation in participant responding that was attributable to which stimulus name they had been assigned (e.g., Seth vs. Todd). According to Monte Carlo simulations, our sample size and model specifications gave us more than $80 \%$ power to detect main effects as small as $\beta=0.10$, to detect two-way interactions as small as $\beta=0.19$, and to detect three-way interactions as small as $\beta=0.37$.

\section{Perceived Heterosexuality}

Our first research question was whether men's heterosexuality would be perceived as more precarious than women's heterosexuality. To test whether this was the case, we subjected perceived heterosexuality scores to the 2 (target race) $\times 2$ (target gender) $\times 2$ (target behavior) analysis described above. Replicating Experiment 1a, this analysis revealed evidence of a twoway interaction between target behavior and target gender: $\beta=0.27,95 \% \mathrm{CI}[0.14,0.39], F(1$, $2905)=17.05, p<.001$. Although targets in general tended to seem "less heterosexual" to participants when they engaged (vs. did not engage) in a same-sex sexual behavior $\left(M_{\text {diff }}=-\right.$ $27.02, \beta=-0.96,95 \% \mathrm{CI}[-1.03,-0.90], F(1,2905)=881.14, p<.001)$, the magnitude of this effect was significantly larger when the targets were men $\left(M_{\text {diff }}=-30.78, \beta=-1.10,95 \% \mathrm{CI}[-\right.$ $1.19,-1.01], F(1,2905)=566.30, p<.001)$ than when they were women $\left(M_{\text {diff }}=-23.26, \beta=-\right.$ $0.83,95 \% \mathrm{CI}[-0.92,-0.74], F(1,2905)=329.64, p<.001)$. Thus, in this nationally 
representative sample, as in the convenience sample reported previously, men's heterosexuality was indeed perceived to be more precarious than women's (see Figure 1).

\section{Figure 1}

Perceived Heterosexuality as a Function of Targets' Sexual Behaviors

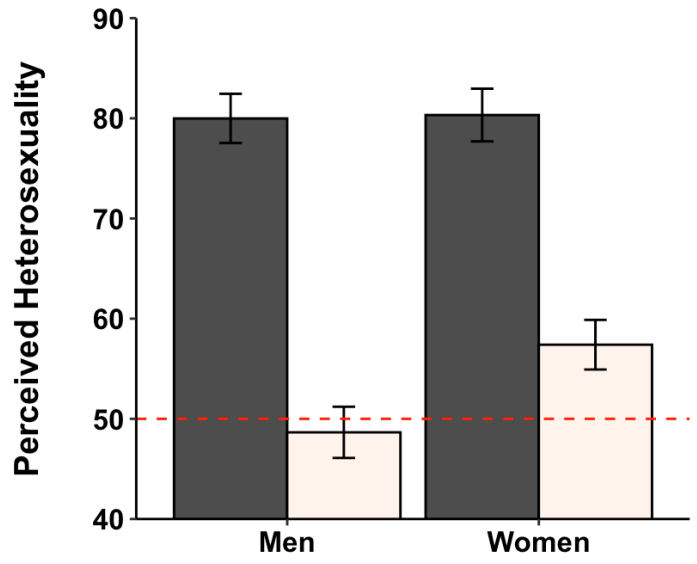

Black Targets

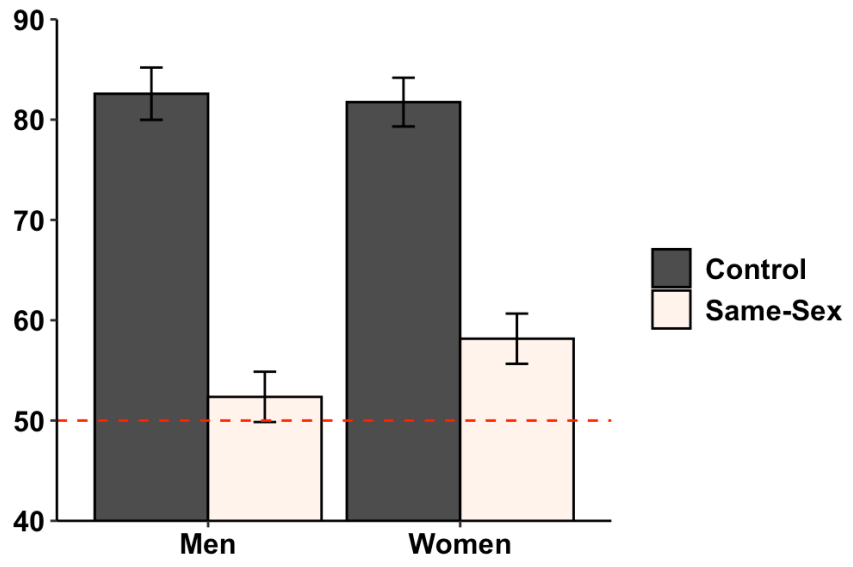

White Targets

Note. Ratings ranged from 0 (certain that targets are not heterosexual) to 100 (certain that targets are heterosexual). Means are enclosed by $95 \%$ confidence intervals (CIs). The dotted line is drawn at scores of 50, which indicate uncertainty as to whether targets were heterosexual.

Our second research question concerned whether the tendency for men's heterosexuality to be perceived as more precarious than women's would be exaggerated when the targets were Black (vs. White). Was there any evidence that this was the case? Surprisingly, and despite the relatively high power that Experiment 2 afforded, there was not. The (target gender) $\times($ target behavior) interaction reported above was not moderated by target race (three-way interaction: $\beta$ $=0.06,95 \% \mathrm{CI}[-0.19,0.32], F(1,2905)=0.24, p=.63)$. This is to say that although men's heterosexuality was perceived to be more precarious than women's, the magnitude of this gender difference did not significantly differ across targets' racial groups. In addition, there was no evidence of a two-way interaction between target behavior and target race: $\beta=-0.01,95 \% \mathrm{CI}[-$ $0.13,0.12], F(1,2905)=0.02, p=.90$. Thus, replicating Experiment $1 \mathrm{~b}$, whether targets were 
Black vs. White did not meaningfully influence the interpretation of these individuals' sexual behaviors - at least not to a degree that we could statistically detect (see Figure 1).

\section{Perceived Bisexuality}

We next investigated whether the patterns identified above hold among perceptions of bisexuality. To do so, bisexuality ratings were subjected to the same 2 (target race) $\times 2$ (target gender $) \times 2$ (target behavior) analysis as above. Replicating Experiment 1a, this model revealed evidence of a two-way interaction between target behavior and target gender: $\beta=-0.16,95 \%$ $\mathrm{CI}[-0.29,-0.03], F(1,2860)=5.78, p=.016$. The nature of this interaction was that although targets in general tended to seem "more bisexual" when they engaged (vs. did not engage) in a same-sex sexual behavior $\left(M_{\text {diff }}=29.46, \beta=0.97,95 \% \mathrm{CI}[0.90,1.03], F(1,2860)=869.90, p<\right.$ $.001)$, the magnitude of this effect was significantly bigger when the targets were men $\left(M_{\text {diff }}=\right.$ $31.87, \beta=1.05,95 \% \mathrm{CI}[0.95,1.14], F(1,2860)=507.78, p<.001)$ than when the targets were women $\left(M_{\text {diff }}=27.06, \beta=0.89,95 \% \mathrm{CI}[0.80,0.98], F(1,2824)=367.64, p<.001\right)$. Thus, once again we found evidence that men's sexual orientations are more precarious than women's (see Figure 2).

What about target race? Was there any evidence that Black vs. White individuals seemed differentially "bisexual" as a result of engaging (vs. not engaging) in same-sex sexual behavior? Again, target race did not appear to influence participants' judgments. Target race did not interact with target behavior on its own [two-way interaction: $\beta=0.03,95 \% \mathrm{CI}[-0.10,0.15]$, $F(1,2860)=0.16, p=.69$ ], nor did it interact with the gender-by-behavior interaction reported above [three-way interaction: $\beta=0.12,95 \% \mathrm{CI}[-0.14,0.38], F(1,2860)=0.84, p=.36]$. Thus, as in Experiment 1b, targets' racial groups did not influence the extent to which their sexualities were regarded to be precarious (see Figure 2). 


\section{Figure 2}

Perceived Bisexuality as a Function of Targets' Sexual Behaviors

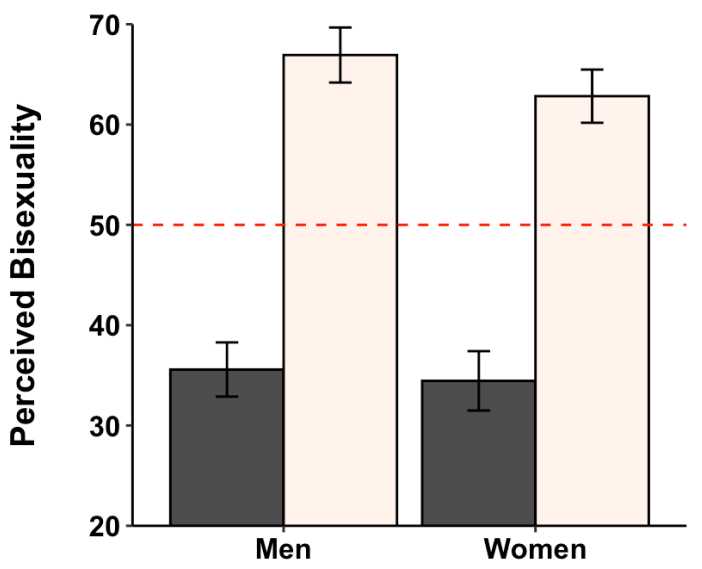

Black Targets

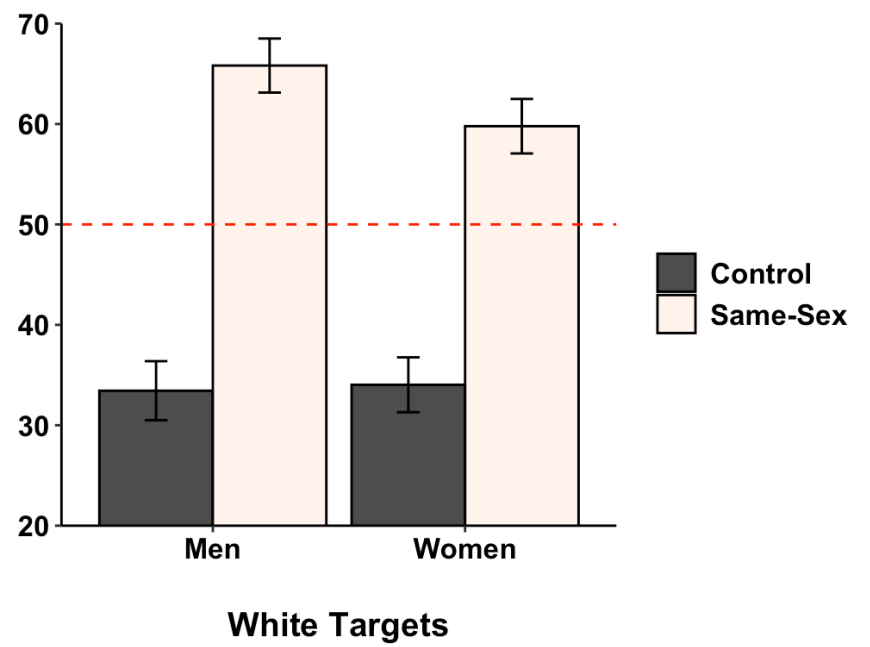

White Targets

Note. Ratings ranged from 0 (certain that targets are not bisexual) to 100 (certain that targets are bisexual). Means are enclosed by $95 \%$ confidence intervals (CIs). The dotted line is drawn at scores of 50, which indicate uncertainty as to whether targets were bisexual.

\section{Perceived Homosexuality}

Finally, we examined whether prior findings related to perceived homosexuality would replicate in Experiment 2. To examine whether this was the case, ratings of how homosexual target individuals seemed were subjected to the same 2 (target race) $\times 2$ (target gender) $\times 2$ (target behavior) analysis as above. Replicating what we observed in Experiment 1a, this model revealed evidence of a two-way interaction between target behavior and target gender: $\beta=-0.34$, $95 \% \mathrm{CI}[-0.48,-0.20], F(1,2824)=22.85, p<.001$. The nature of this interaction was that although all targets seemed "more homosexual" when they engaged (vs. did not engage) in a same-sex sexual behavior $\left(M_{\text {diff }}=18.82, \beta=0.67,95 \% \mathrm{CI}[0.60,0.73], F(1,2824)=354.98, p<\right.$ $.001)$, the magnitude of this effect was bigger when the targets were men $\left(M_{\text {diff }}=23.60, \beta=0.83\right.$, $95 \% \mathrm{CI}[0.74,0.93], F(1,2824)=279.12, p<.001)$ than when they were women $\left(M_{\text {diff }}=14.05, \beta\right.$ $=0.50,95 \% \mathrm{CI}[0.40,0.59], F(1,2824)=98.80, p<.001)$. Thus, is this nationally representative sample of respondents, as in our MTurk sample of respondents, we found that men who engaged 
in a single same-sex sexual behavior (vs. not) seemed "gayer" than women who did the same (see Figure 3).

\section{Figure 3}

Perceived Homosexuality as a Function of Targets' Sexual Behaviors
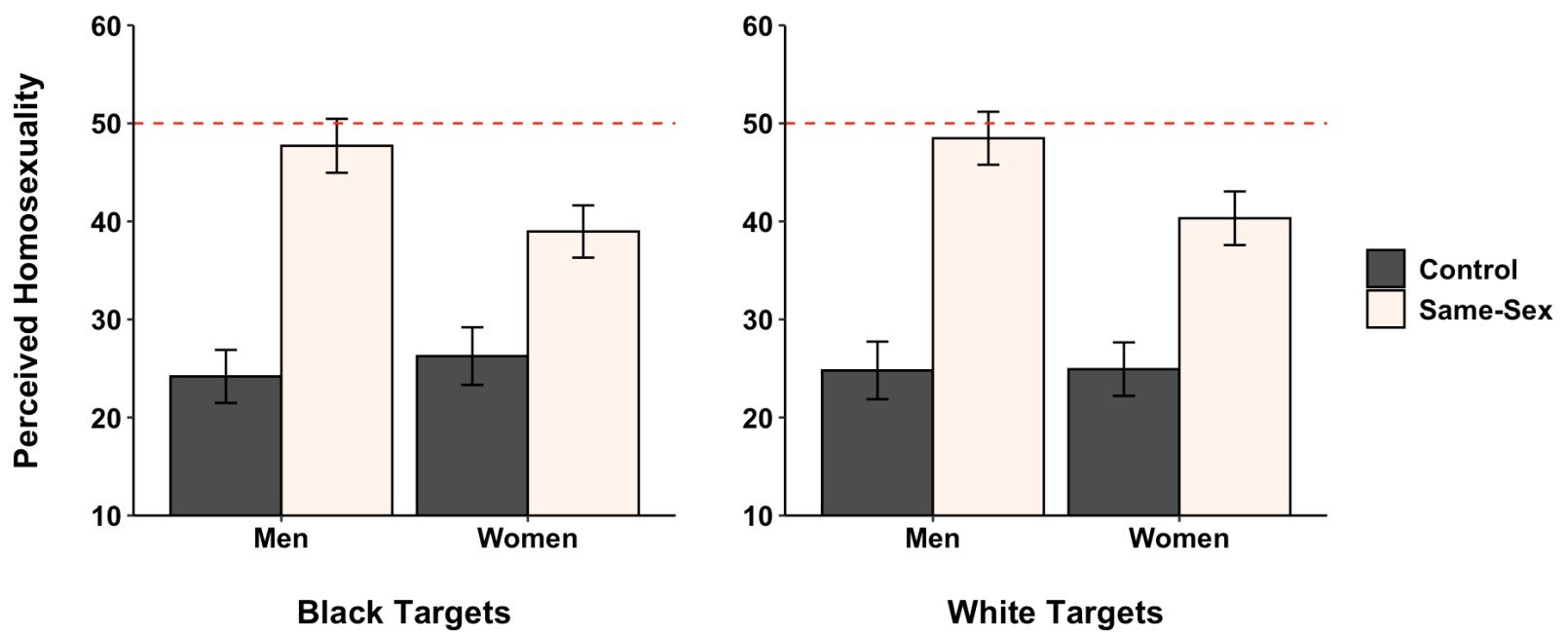

Note. Ratings ranged from 0 (certain that targets are not homosexual) to 100 (certain that targets are homosexual). Means are enclosed by $95 \%$ confidence intervals (CIs). The dotted line is drawn at scores of 50, which indicate uncertainty as to whether targets were homosexual.

Was there any evidence that these effects depended on targets' racial groups? As in previous analyses, this analysis revealed no evidence that target race interacted with target behavior [two-way interaction: $\beta=-0.05,95 \% \mathrm{CI}[-0.19,0.09], F(1,2824)=0.51, p=.48]$, nor that the gender-by-behavior interaction reported above was moderated by target race [three-way interaction: $\beta=-0.09,95 \% \mathrm{CI}[-0.37,0.19], F(1,2824)=0.40, p=.53]$. Thus, ratings of perceived homosexuality — much like ratings of perceived heterosexuality and perceived bisexuality—revealed that targets' racial groups did not influence the degree to which targets' sexualities were malleable in the eyes of perceivers. Instead, perceivers' interpretations of targets' behaviors appeared to depend only on targets' gender groups. For summary statistics for all conditions in Experiment 2, see Table 4. 
Table 4

Means and Standard Errors around Judgments of Sexual Orientation in Each Condition

\begin{tabular}{|c|c|c|c|c|c|}
\hline \multicolumn{3}{|c|}{$\begin{array}{c}\text { Experiment } 2 \\
(N=\mathbf{3 , 0 1 0})\end{array}$} & \multicolumn{3}{|c|}{$\begin{array}{c}\text { Perceptions that Targets Were Each of Three } \\
\text { Specified Sexual Orientations }\end{array}$} \\
\hline $\begin{array}{l}\text { Target } \\
\text { Race }\end{array}$ & $\begin{array}{l}\text { Target } \\
\text { Gender }\end{array}$ & $\begin{array}{l}\text { Target } \\
\text { Behavior }\end{array}$ & Heterosexual & Bisexual & Homosexual \\
\hline Black & Man & Control & $79.99(1.25)$ & $35.58(1.38)$ & $24.19(1.38)$ \\
\hline Black & Man & Same-sex & $48.65(1.30)$ & $66.93(1.40)$ & $47.71(1.40)$ \\
\hline Black & Woman & Control & $80.33(1.34)$ & $34.45(1.51)$ & $26.26(1.50)$ \\
\hline Black & Woman & Same-sex & $57.40(1.26)$ & $62.83(1.35)$ & $38.97(1.36)$ \\
\hline White & Man & Control & $82.59(1.33)$ & $33.44(1.50)$ & $24.80(1.50)$ \\
\hline White & Man & Same-sex & $52.36(1.28)$ & $65.82(1.37)$ & $48.48(1.38)$ \\
\hline White & Woman & Control & $81.75(1.24)$ & 34.03 (1.39) & $24.93(1.39)$ \\
\hline White & Woman & Same-sex & $58.16(1.28)$ & $59.78(1.39)$ & $40.32(1.40)$ \\
\hline
\end{tabular}

Note. Means are outside of parentheses; standard errors around those means are within. Scores of 0 indicate certainty that targets are not a given sexual orientation; scores of 50 indicate uncertainty about whether targets are a given sexual orientation; and scores of 100 indicate certainty that targets are a given sexual orientation.

\section{Equivalence Tests: Zero Impact of Target Race on Perceptions of Sexual Behavior?}

In Experiment 2, which had markedly higher statistical power than Experiments 1a and 1b, we found no evidence that targets' racial groups influenced perceptions of their sexual behavior. But how null were these effects? In a final set of analyses, we implemented an equivalence testing procedure called the two one-sided tests (TOST) procedure (Lakens, 2017; Lakens et al., 2018). In a typical TOST procedure, researchers conduct two one-sided $t$-tests to examine whether an observed effect is significantly closer to zero than it is to the least non-zero effects researchers had adequate power to detect. In our case, we examined whether each of the race $\times$ behavior interactions we observed — all of which were null—were significantly closer to zero than they were to $\beta$ s of -0.19 and 0.19 , respectively (that is, to the smallest two-way interactions that we had at least $80 \%$ power to detect). Likewise, we examined whether each of the race $\times$ gender $\times$ behavior interactions we observed - all of which were also null-were 
significantly closer to zero than they were to $\beta$ s of -0.37 and 0.37 , respectively (that is, to the smallest three-way interactions that we had at least $80 \%$ power to detect). If all one-sided $t$-tests from the TOST procedure are themselves statistically significant, this suggests not only that the interactions with target race that we observed are null, but that they are so null that they are practically equivalent to zero.

\section{Table 5}

Equivalence Testing Results of Two- and Three-Way Interactions with Target Race.

\begin{tabular}{|c|c|c|c|c|}
\hline $\begin{array}{l}\text { Dependent } \\
\text { Variable }\end{array}$ & $\begin{array}{l}\text { Effect Test of } \\
\text { Interest }\end{array}$ & $\begin{array}{l}\text { Observed } \\
\text { Effect }\end{array}$ & $\begin{array}{c}\text { Detectable } \\
\text { Effect }\end{array}$ & $\begin{array}{c}\text { Equivalence Test } \\
\text { (TOST) Result }\end{array}$ \\
\hline \multirow[t]{2}{*}{ Heterosexuality } & race $\times$ behavior & $\beta=-0.01$ & $\beta=0.19$ & $t(2905)=2.78, p=.003$ \\
\hline & $\begin{array}{l}\text { race } \times \text { gender } \times \\
\text { behavior }\end{array}$ & $\beta=0.06$ & $\beta=0.37$ & $t(2905)=2.39, p=.008$ \\
\hline \multirow[t]{2}{*}{ Bisexuality } & race $\times$ behavior & $\beta=0.03$ & $\beta=0.19$ & $t(2860)=2.44, p=.007$ \\
\hline & $\begin{array}{l}\text { race } \times \text { gender } \times \\
\text { behavior }\end{array}$ & $\beta=0.12$ & $\beta=0.37$ & $t(2860)=1.91, p=.028$ \\
\hline \multirow[t]{2}{*}{ Homosexuality } & race $\times$ behavior & $\beta=-0.05$ & $\beta=0.19$ & $t(2824)=1.98, p=.024$ \\
\hline & $\begin{array}{l}\text { race } \times \text { gender } \times \\
\text { behavior }\end{array}$ & $\beta=-0.09$ & $\beta=0.37$ & $t(2824)=1.98, p=.024$ \\
\hline
\end{tabular}

Note. Observed Effect $=$ the observed standard beta for a particular two- or three-way interaction. Detectable Effect = the smallest standard beta for two- or three-way interactions that we had at least $80 \%$ power to detect. Equivalence Test (TOST) Result $=$ a one-sided test of whether the observed effect is significantly closer to zero than to the smallest non-zero effect we had at least $80 \%$ power to detect. Significant TOST results suggest that observed effects are practically equivalent to zero (Lakens, 2017).

What did the results of this equivalence testing procedure reveal? The results of this procedure revealed that all observed race-by-behavior interactions - as well as all observed raceby-gender-by-behavior interactions - were significantly closer to zero than they were to the least non-zero effects we had adequate power to detect. This was true whether the dependent variable in question was perceived heterosexuality (all $p s \leq .008$ ), perceived bisexuality (all $p s \leq .028$ ), or perceived homosexuality (all $p s \leq .024)$. In other words, there was evidence that targets' racial 
groups had practically zero impact on how precarious their heterosexuality was regarded to be in the eyes of perceivers (see Table 5 for all TOST results).

\section{Discussion}

Experiment 2 was designed to be an improvement over Experiments $1 \mathrm{a}$ and $1 \mathrm{~b}$ in several regards. First, Experiment 2 had a per-condition sample size that was nearly quadruple the percondition sample size of Experiments 1a and 1b. Second, Experiment 2 was conducted on a probability-based, nationally representative sample of U.S. adults rather than on a convenience sample of U.S. adults (as in Experiments 1a and 1b). Third, Experiment 2 included Black women in its experimental design, which afforded a full test of whether a target person's gender and race operate in tandem to influence the extent to which that person's heterosexuality is perceived to be precarious. These improvements made Experiment 2 more highly powered, more generalizable, and better equipped to answer our research questions than Experiments 1a and $1 \mathrm{~b}$.

Experiment 2's statistical conclusions paralleled those of Experiments 1a and 1b. First, Experiment 2 replicated the finding that perceivers more readily question the heterosexuality of men than the heterosexuality of women when these individuals engage (vs. do not engage) in a single same-sex sexual behavior. Second, and consistent with the implications of Experiment 1b, Experiment 2 revealed no evidence that this bias was moderated by whether the target individuals were Black vs. White. In fact, targets' racial groups - on their own, or in tandem with gender — had such little influence on how precarious targets' sexualities were judged to be that the influence of target race was, in all cases, significantly closer to zero than it was to the least non-zero effects we had adequate power to detect (Lakens, 2017). ${ }^{8}$

\footnotetext{
${ }^{8}$ For exploratory purposes, we also examined whether participants' own racial groups — whether they identified as White vs. Black - moderated any of the reported findings. Generally speaking, we found no compelling evidence that our findings were moderated by participant race. Though notably, statistical power for detecting such interactions was limited (see pp. 8-12 of the online supplement for a full discussion).
} 


\section{General Discussion}

The principal aim of this manuscript was to examine whether (1) men's heterosexuality would be perceived as more precarious — or losable in the eyes of perceivers - than women's, and if so, (2) whether this effect would be exaggerated when the targets were Black rather than White. Results from three experiments (one of which was nationally representative of the U.S. adult population; total $N=3,811$ ) revealed that indeed, men who engage in a single same-sex sexual behavior (vs. not) are judged as "less heterosexual," "more bisexual," and "more homosexual" than women who do the same. This finding is sensible from the perspective that in the U.S., men's gender identities are more precarious than women's (Bosson et al., 2013), and that one's gender identity presumes heterosexuality by default (Lick \& Johnson, 2016).

However, these data revealed no evidence that this tendency was exaggerated when the targets in question were Black rather than White. Instead, we found that targets' race appeared to fade into the perceptual background. The degree to which sexual orientation was pliable in the eyes of perceivers was unmoderated by race on its own, and it was likewise unmoderated by race and gender in tandem. This latter finding is surprising in light of the observation that gender and race often jointly impact person perception (e.g., Hall et al., 2019; Rosette et al., 2018).

\section{Theoretical Contributions}

What are the theoretical implications of these findings? As noted from the outset, we expected that a person's racial group would, in tandem with their gender group, influence the extent to which their heterosexuality would be regarded as precarious. This expectation was based on the specific observations that (a) Black men tend to be stereotyped as more masculine and more heterosexual than White men (Carnaghi et al., 2020; Hall et al., 2015), and that (b) Black women tend to be overlooked and ignored to a greater extent than White women (Purdie- 
Vaughns \& Eibach, 2008; Sesko \& Biernat, 2010). Taken together, these findings suggest that same-sex sexual behavior ought to have been more noticeable among Black men than among White men, and that same-sex sexual behavior ought to have been less noticeable among Black women than among White women. Yet instead, we found that race did not influence perceivers' impressions of targets' sexual behavior — so much so that the influence of targets' racial groups on perceivers' impressions of sexual behavior was practically equivalent to zero. This observation raises a question. Why didn't race matter in the context of the present experiments?

An emerging theoretical perspective on intersectional stereotyping argues that perceivers may engage in intersectional stereotyping in a compartmentalized way-meaning that perceivers may sometimes attend to race alone, at other times they may attend to gender alone, and at still other times they may attend to intersectional identities specifically (e.g., race and gender simultaneously; Petsko \& Bodenhausen, 2020; Remedios \& Vinluan, in press). For example, there is evidence that being in a context that is stereotypically associated with the concept of race can sharpen perceivers' attention on race so strongly that they stop — in these momentsstereotyping targets on the basis of targets' age groups (Todd et al., 2016) or on the basis of targets' sexual orientation groups (Agerström et al., 2021; Petsko \& Bodenhausen, 2019a). This theoretical perspective, which was recently incorporated into a formal model of intersectional stereotyping called the lens model (Petsko et al., 2022), stands in sharp contrast to integration accounts of intersectional stereotyping, which presume that perceivers attend to all social identities at once when engaging in intersectional stereotyping (e.g., Freeman et al., 2020). Thus, the theoretical utility of these findings is that they add to a growing body of evidence in favor of compartmentalization models. In certain social contexts, one identity may come into perceivers' focus so strongly that other identities — at least for the moment - fall to the perceptual wayside. 


\section{Limitations and Future Directions}

If perceivers in the present experiment felt that the vignette was more stereotypically associated with the concept of gender than with the concept of race, this could explain why judgments of sexual precariousness depended on targets' gender groups, but not—in the context of the present experiments — on targets' racial groups. Future research should examine this theoretical possibility directly, as a limitation of the present manuscript is that it cannot test this mechanism. It would be useful to know, for example, whether perceivers generally think of sexual behavior as being more relevant to the concept of gender than to the concept of race (e.g., Kite \& Deaux, 1987). Likewise, it would be useful to know whether changing the experimental context—by priming race rather than gender — could in turn change the pattern of results reported here. If race were made more salient to perceivers, we might have seen that targets' race influenced the interpretation of their behavior more than targets' gender, or alternatively, that targets' race and gender mutually informed perceivers' judgments of targets' behavior, as we had anticipated they would. A set of experiments along these lines would be useful for understanding a) how it is that different identities come to influence perceptions of sexual precarity, and b) when it is that these different identities will come into the perceptual foreground.

How are we to square the reported findings with the observation that in the U.S., people typically view sexuality as more essentialized (and less pliable) among men than among women (Baumeister, 2000; Peplau, 2003)? In general, we view the reported findings as compatible with prior research on lay beliefs about sexual essentialism. Indeed, perceivers might have regarded men's (vs. women's) same-sex sexual behavior as more diagnostic of men's (vs. women's) underlying sexual identities not in spite of this lay belief, but because of this lay belief. To the extent that perceivers believe men's sexual preferences are more essentialized than women's, 
they may view men's same-sex sexual behaviors as particularly indicative of underlying sexual preferences. Future research should investigate this possibility, as a limitation of the present research is that it did not measure constructs that might help to identify the cognitive underpinnings of sexual precarity.

On a related note, the present research did not measure perceived precarity of targets' masculinity and femininity alongside perceived precarity of targets' sexual identities. An assumption made throughout this manuscript is that men's heterosexuality is perceived as more precarious than women's because men's gender identities (which presume heterosexuality by default; Alt et al., 2020; Lick \& Johnson, 2016) are themselves perceived as more precarious than women's. This is to say that precariousness of one identity (one's gender standing) necessitates precariousness of the other (one's heterosexuality standing). Yet a limitation of the data provided is that they do not enable a test of how correlated these two types of precariousness may be in the minds of perceivers. Thus, an open question for future research concerns whether acts of heterosexuality are themselves perceived as acts of manhood/womanhood, such that the two are perceived as fundamentally intertwined (as we have been suggesting), or whether the two can be "lost" independently from each other.

A final limitation of the present experiments is that they all rely on a similar methodology of assessing the precariousness of sexual identities - a vignette task. Although we chose this method so that the present findings could be interpreted against the backdrop of other findings in this research area (Mize \& Manago, 2018), questions remain as to how judgments of sexual precarity unfold in more naturalistic settings. In the wider world, perceivers often have more than just a target person's name to use as a basis for engaging in race categorization. With increased perceptual information that makes race salient (e.g., visual information, targets' self- 
identifications), it is entirely possible that targets' racial groups may be less likely to fade into the perceptual background. Furthermore, names themselves are imperfect proxies for race (Gaddis, 2019), and it may be the case that using names_rather than using more externally valid indicators of targets' race—can at least partly explain why race did not influence the interpretation of targets' sexual behaviors. Future research should expand on the present findings by examining the extent to which these findings, and lens dynamics more generally, hold up in the wider world.

\section{Concluding Remarks}

In various societies, men's gender identities are regarded as more precarious than women's gender identities (Bosson et al., 2013; Gilmore, 1990). The findings presented here suggest that heterosexuality—which is often implicated in men and women's gender identities (Herek \& McLemore, 2013; Lick \& Johnson, 2016)—is likewise regarded as more precarious for men than for women. Moreover, these findings suggest that in certain contexts, perceivers may focus on men's and women's gender identities so strongly that they cease to focus, at least for the moment, on these men's and women's racial identities. Although this observation may seem surprising on its surface, it is sensible from the viewpoint that different lenses for viewing others can come in and out of focus as a matter of social context (Petsko et al., 2022). Although we very often view other people in light of the rich complexity of their intersecting identities (Hall et al., 2019), we may occasionally restrict our focus to just one identity at a time. Identifying when this process happens - and what implications it may have for those around us - will be critical to developing a more thorough understanding of intersectional person perception. 


\section{References}

Agerström, J., Carlsson, M., \& Strinić, A. (2022). Intersected groups and discriminatory everyday behavior. Social Psychology, 52, 351-361. https://doi.org/10.1027/18649335/a000464

Alt, N. P., Lick, D. J., \& Johnson, K. L. (2020). The straight categorization bias: A motivated and altruistic reasoning account. Journal of Personality and Social Psychology, 119, 1266-1289. https://doi.org/10.1037/pspi0000232

Baumeister, R. F. (2000). Gender differences in erotic plasticity. Psychological Bulletin, 126, 347-374.

Bolger, N., Stadler, G., \& Laurenceau, J. P. (2012). Power analysis for intensive longitudinal studies. In M. R. Mehl \& T. S. Conner (Eds.), Handbook of research methods for studying daily life (pp. 285-301). New York, NY: Guilford Press.

Bosson, J. K., Vandello, J. A., \& Caswell, T. A. (2013). Precarious manhood. In M. K. Ryan, \& N. R. Branscombe (Eds.), The SAGE handbook of gender and psychology (pp. 115-128). SAGE Publishing. https://doi.org/10.4135/9781446269930.n8

Carnaghi, A., Stragá, M., Coladonato, R., Bianchi, M., \& Piccoli, V. (2020). Extrapolating stereotypical information on sexual orientation from race categories: The case of Black and Asian men. Psychology of Men \& Masculinities, 21, 224-234. https://doi.org/10.1037/men0000225

Cole, E. R. (2009). Intersectionality and research in psychology. American Psychologist, 64, 170-180. https://doi.org/10.1037/a0014564

Craig, M., Druckman, J., \& Freese, J. (2022, November 2022). Time-sharing experiments for the social sciences. https://www.tessexperiments.org

Crenshaw, K. (1991). Mapping the margins: Intersectionality, identity politics, and violence against women of color. Stanford Law Review, 43, 1241-1299. https://doi.org/10.2307/1229039

DiMuccio, S. H., \& Knowles, E. D. (2021). Precarious manhood predicts support for aggressive policies and politics. Personality and Social Psychology Bulletin, 47, 1169-1187. https://doi.org/10.1177/0146167220963577 
Freeman, J. B., Penner, A. M., Saperstein, A., Scheutz, M., \& Ambady, N. (2011). Looking the part: Social status cues shape race perception. PloS ONE, 6, 1-10. https://doi.org/10.1371/journal.pone.0025107

Freeman, J. B., Stolier, R. M., \& Brooks, J. A. (2020). Dynamic interactive theory as a domaingeneral account of social perception. Advances in Experimental Social Psychology, 61, 237-287.

Gaddis, S. M. (2017). How Black are Lakisha and Jamal? Racial perceptions from names used in correspondence audit studies. Sociological Science, 4, 469-489. https://doi.org/10.15195/v4.a19

Gaddis, S. M. (2019). Signaling class: Two survey experiments examining social class perceptions from names used in racial-bias experiments. Retrieved from SSRN: https://ssrn.com/abstract $=3350739$

Galinsky, A. D., Hall, E. V., \& Cuddy, A. J. C. (2013). Gendered races: Implications for interracial marriage, leadership selection, and athletic participation. Psychological Science, 24, 498-506. https://doi.org/10.1177/0956797612457783

Gilmore, D. D. (1990). Manhood in the making: Cultural concepts of masculinity. Yale University Press.

Goff, P. A., Thomas, M. A., \& Jackson, M. C. (2008). “Ain’t I a woman?”: Towards an intersectional approach to person perception and group-based harms. Sex Roles, 59, 392403. https://doi.org/10.1007/s11199-008-9505-4

Green, P., \& MacLeod, C. J. (2016). SIMR: An R package for power analysis of generalized linear mixed models by simulation. Methods in Ecology and Evolution, 7, 493-498. https://doi.org/10.1111/2041-210X.12504

Hall, E. V., Galinsky, A. D., \& Phillips, K. W. (2015). Gender profiling: A gendered race perspective on person-position fit. Personality and Social Psychology Bulletin, 41, 853868. https://doi.org/10.1177/0146167215580779

Hall, E. V., Hall, A. V., Galinsky, A. D., \& Phillips, K. W. (2019). MOSAIC: A model of stereotyping through associated and intersectional categories. Academy of Management Review, 44, 643-672. https://doi.org/10.5465/amr.2017.0109

Herek, G. M., \& McLemore, K. A. (2013). Sexual prejudice. Annual Review of Psychology, 64, 309-333. https://doi.org/10.1146/annurev-psych-113011-143826 
Johnson, K. L., Freeman, J. B., \& Pauker, K. (2012). Race is gendered: How covarying phenotypes and stereotypes bias sex categorization. Journal of Personality and Social Psychology, 102, 116-131. https://doi.org/10.1037/a0025335

Johnson, K. L, \& Ghavami, N. (2011). At the crossroads of conspicuous and concealable: What race categories communicate about sexual orientation. PLOS ONE, 6, e18025. https://doi.org/10.1371/journal.pone.0018025

Johnson, L. L., \& Lipsett-Rivera, S. (1998). The faces of honor: Sex, shame, and violence in colonial Latin America. University of New Mexico Press.

Judd, C. M., Westfall, J., \& Kenny, D. A. (2012). Treating stimuli as a random factor in social psychology: A new and comprehensive solution to a pervasive but largely ignored problem. Journal of Personality and Social Psychology, 103, 54-69. https://doi.org/10.1037/a0028347

Katz, D., \& Braly, K. (1933). Racial stereotypes of one hundred college students. Journal of Abnormal and Social Psychology, 28, 280-290.

King, D. K. (1988). Multiple jeopardy, multiple consciousness: The context of a Black feminist ideology. Signs: Journal of Women in Culture and Society, 14, 42-72. https://doi.org/10.1086/494491

Kite, M. E., \& Deaux, K. (1987). Gender belief systems: Homosexuality and the implicit inversion theory. Psychology of Women Quarterly, 11, 83-96. https://doi.org/10.1111/j.1471-6402.1987.tb00776.x

Lakens, D., Scheel, A. M., \& Isager, P. M. (2018). Equivalence testing for psychological research: A tutorial. Advances in Methods and Practices in Psychological Science, 1 , 259-269.

Lakens, D. (2017). Equivalence tests: A practical primer for $t$ tests, correlations, and metaanalyses. Social Psychological and Personality Science, 8, 355-362.

Lick, D. J., \& Johnson, K. L. (2016). Straight until proven gay: A systematic bias toward straight categorizations in sexual orientation judgments. Journal of Personality and Social Psychology, 110, 801-817. https://doi.org/10.1037/pspa0000052

Mize, T. D., \& Manago, B. (2018). Precarious sexuality: How men and women are differentially categorized for similar sexual behavior. American Sociological Review, 83, 305-330. https://doi.org/10.1177/0003122418759544 
Neel, R., \& Lassetter, B. (2019). The stigma of perceived irrelevance: An affordancemanagement theory of interpersonal invisibility. Psychological Review, 126, 634-659. https://doi.org/10.1037/rev0000143

Parent, M. C., Kalenkosi, C. M., \& Cardella, E. (2018). Risky business: Precarious manhood and investment portfolio decisions. Psychology of Men and Masculinity, 19, 195-202. https://doi.org/10.1037/men0000089

Peplau, L. A. (2003). Human sexuality: How do men and women differ? Current Directions in Psychological Science, 12, 37-40.

Petsko, C. D., \& Bodenhausen, G. V. (2020). Multifarious person perception: How social perceivers manage the complexity of intersectional targets. Social and Personality Psychology Compass, 14, e12518. https://doi.org/10.1111/spc3.12518

Petsko, C. D., \& Bodenhausen, G. V. (2019). Race-crime congruency effects revisited: Do we take defendants' sexual orientation into account? Social Psychological and Personality Science, 10, 73-81.

Petsko, C. D., \& Bodenhausen, G. V. (2019). Racial stereotyping of gay men: Can a minority sexual orientation erase race? Journal of Experimental Social Psychology, 83, 37-54. https://doi.org/10.1016/j.jesp.2019.03.002

Petsko, C. D., Rosette, A. S., \& Bodenhausen, G. V. (2022). Through the looking glass: A lensbased account of intersectional stereotyping. Journal of Personality and Social Psychology. https://doi.org/10.1037/pspi0000382

Ponce de Leon, R., \& Rosette, A. S. (2022). "Invisible" discrimination: Divergent outcomes for the non-prototypicality of Black women. Academy of Management Journal. https://doi.org/10.5465/amj.2020.1623

Purdie-Vaughns, V., \& Eibach, R. P. (2008). Intersectional invisibility: The distinctive advantages and disadvantages of multiple subordinate-group identities. Sex Roles: A Journal of Research, 59, 377-391. https://doi.org/10.1007/s11199-008-9424-4

Remedios, J. D., \& Vinluan, A. C. (in press). Intersectionality in social cognition. In D. E. Carlston, K. Johnson, \& K. Hugenberg (Eds.), Oxford handbook of social cognition $\left(2^{\text {nd }}\right.$ ed.). 
Rosette, A. S., Ponce de Leon, R., Koval, C. Z., \& Harrison, D. A. (2018). Intersectionality: Connecting experiences of gender with race at work. Research in Organizational Behavior, 38, 1-22. https://doi.org/10.1016/j.riob.2018.12.002

Sesko, A. K., \& Biernat, M. (2010). Prototypes of race and gender: The invisibility of Black women. Journal of Experimental Social Psychology, 46, 356-360. https://doi.org/10.1016/j.jesp.2009.10.016

Todd, A. R., Thiem, K. C., \& Neel, R. (2016). Does seeing faces of young Black boys facilitate the identification of threatening stimuli? Psychological Science, 27, 384-393. https://doi.org/10.1177/0956797615624492

Tornello, S. L., \& Matsik, J. L. (2020). Do actions speak louder than words? Perceptions of women's and men's branched and coincident configurations of sexual identities and behaviours. Psychology \& Sexuality, 11, 180-197.

Vandello, J. A., \& Bosson, J. K. (2013). Hard won and easily lost: A review and synthesis of theory and research on precarious manhood. Psychology of Men \& Masculinity, 14, 101113. https://doi.org/10.1037/a0029826

Vandello, J. A., Bosson, J. K., Cohen, D., Burnaford, R. M., \& Weaver, J. R. (2008). Precarious manhood. Journal of Personality and Social Psychology, 95, 1325-1339. https://doi.org/10.1037/a0012453

West, K., Borras-Guevara, M. L., Morton, T., \& Greenland, K. (2021). Fragile heterosexuality. Social Psychology, 52, 143-161. 